\title{
Perspectives on: Supercritical Fluid Technology for 3D Tissue Engineering Scaffold Applications
}

\author{
Ana Rita C. DuARte, ${ }^{1,2}$ JoÃo F. MANO ${ }^{1,2, *}$ AND Rui L. REIS ${ }^{1,2}$ \\ ${ }^{1} 3 B$ 's Research Group - Biomaterials, Biodegradables and \\ Biomimetics, Department of Polymer Engineering, University \\ of Minho, Headquarters of the European Institute of Excellence \\ on Tissue Engineering and Regenerative Medicine, AvePark \\ Zona Industrial da Gandra, S. Cláudio do Barco \\ 4806-909 Caldas das Taipas, Guimarães, Portugal \\ ${ }^{2} I B B$ - Institute for Biotechnology and Bioengineering \\ PT Associated Laboratory (Laboratório Associado), Portugal
}

\begin{abstract}
Supercritical fluid technology has proven to be useful for many pharmaceutical applications and is now emerging as an alternative to conventional processes for the preparation of 3D structures and injectable particles suitable to be used in regenerative medicine. A current overview of the basic principles underlying supercritical fluid technology, the state of the art and future potential of this technology are presented.
\end{abstract}

KEY WORDS: scaffolds, tissue engineering, drug delivery, supercritical fluids, polymer, phase inversion, foaming, impregnation, sterilization.

\section{INTRODUCTION}

The field of tissue engineering has evolved greatly since the 1 concept of combining active compounds and scaffolds to create

*Author to whom correspondence should be addressed. E-mail: jmano@dep.uminho.pt Figures 1 and 2 appear in color online: http://jbc.sagepub.com 
artificial tissues. The emerging generation of engineered tissues incorporates the development of scaffolds that are infused with bioactive molecules to create an environment for the cellular function (proliferation and differentiation factors) or to interact with the contact tissues (drugs delivery, such as anti-inflammatory agents or antibiotics). Hence, the strategy is to mimic matrices and provide the necessary information or signaling for cell attachment, proliferation, and differentiation to meet the requirements for dynamic tissue engineering [1,2].

One of the most important stages of tissue engineering is the design and processing of a 3D structure, with high porosity, high interconnectivity between the porous and uniform distribution. A variety of processing techniques have been developed [3]; the main disadvantages of these methods are the use of large quantities of organic solvents or high temperatures required. Therefore, there is a need to develop new technologies able to overcome these drawbacks. The use of supercritical fluid could be an alternative to the conventional processes and several techniques are described in the literature for processing of biopolymers and biomedical devices using this technology.

\section{SUPERCRITICAL FLUIDS: BASIC PRINCIPLES}

A supercritical fluid (SCF) can be defined as a dense phase at which the pressure and temperature are above the critical point of a gas. At the critical point a single phase exists with properties common to liquids, namely density, viscosity, compressibility, and mass diffusion coefficient [4]. Different supercritical fluids are available but not all are suitable for certain applications. The choice of the SCF depends on its physicochemical properties [5].

Carbon dioxide is the most commonly used supercritical fluid as its critical parameters, specially its low critical temperature, makes it very attractive for processing thermosensitive compounds, such as pharmaceuticals and other bioactive compounds. It presents other important advantages, since it is environmentally benign, nontoxic, nonflammable, noncorrosive, readily available, and inexpensive. Furthermore, carbon dioxide has the status of a GRAS (Generally Regarded as Safe) solvent. The elimination of carbon dioxide and the recovery of final products are easier (no residue is left and a dry solid product is easily obtained, just by manipulating the pressure), thus leading to processes with less energy consumption. Carbon dioxide can be recovered and reused, and, therefore, does not contribute to the greenhouse effect.

In all products for medical and pharmaceutical applications, the presence of residual organic solvents is rigorously controlled by 
international safety regulations, therefore, it is necessary to warrant the complete removal and absence of these substances, without exposing drugs to high temperatures, which may degrade them [6]. Thus the use of supercritical fluid technology, such as supercritical carbon dioxide, appears to be a viable alternative to the traditional processing methods.

\section{PREPARATION OF 3D SCAFFOLDS}

Several techniques are reported in the literature for the preparation of 3D scaffolds [7]. Conventionally, 3D structures can be obtained by processes such as solvent casting-particle leaching [8], freeze-dryingparticle leaching [9], thermally induced phase separation [10], compression molding [11], injection molding [12,13], extrusion [14], foaming [15], wet spinning [16] and electrospinning [17], as well as others.

The advantages of these processes have, however, to be weighed against the fact that these normally involve the use of large amounts of organic solvents, and further purification and drying steps are often needed. Additionally, some of these techniques are often performed at high temperatures, which may degrade thermo-labile components, such as pharmaceutical drugs and bioactive agents. For these reasons, new processes that are able to avoid or reduce the use of organic solvents and that operate under mild conditions are of interest. Supercritical fluids are an attractive technology platform that qualify to overcome these drawbacks. The most commonly used techniques for the preparation of $3 \mathrm{D}$ scaffolds for tissue engineering purposes include gas foaming and phase inversion processes.

\section{Gas Foaming}

Gas foaming takes advantage of the plasticizing properties of carbon dioxide. The most relevant phase change for polymer processing is the glass transition temperature ( $T_{\mathrm{g}}$, the glass-to-rubber transition). It is qualitatively known for many years that the compression of solid materials with gases alter the phase equilibria of pure component, in particular, the dissolution of carbon dioxide lowers the $T_{\mathrm{g}}$ of amorphous polymers, and in some cases, significantly. The reduction of glass transition temperature is a thermodynamic effect due to intermolecular interactions between carbon dioxide and the polymer. Stronger interactions enhance $T_{\mathrm{g}}$ depression, as does chain flexibility. In the gas foaming technique, the polymer is exposed to carbon dioxide to plasticize it by reducing the glass transition temperature. On venting the $\mathrm{CO}_{2}$, by depressurization, the thermodynamic instability causes 
super saturation of the carbon dioxide dissolved in the polymer matrix and hence, nucleation of cells occurs (Figure 1) [18]. The use of this technique is, however, limited to amorphous polymers or semicrystalline polymers with low $T_{\mathrm{g}}$.

Represented in Figure 2 is an example of the foaming effect on a methacrylate-based copolymer. The material on the left-hand side was exposed to carbon dioxide for 10 minute. Then depressurizing the system causes the polymer to foam and the final result is illustrated in Figure 2 (right-hand side).

This technique has the potential to be used to prepare 3D materials having high porosity and interconnected pores with a wide range of applications in the field of tissue engineering and regenerative medicine.

Mooney and coworkers [19,20] were the first to describe the use of supercritical foaming for the preparation of macroporous scaffolds for tissue engineering applications. Interconnected porous structures of $\mathrm{P}_{\mathrm{D}, \mathrm{L}}$ LGA were successfully produced. Much of the research in this field is based on homopolymers and copolymers of lactic and glycolic acids as they are attractive candidates for the fabrication of tissue engineering scaffolds [21,22]. Bioresorbable ceramic-polymer composites were also prepared and are described by Mathieu et al. [23] and Georgiou et al. [24]. The ability to process composite matrixes of ceramics and polymers

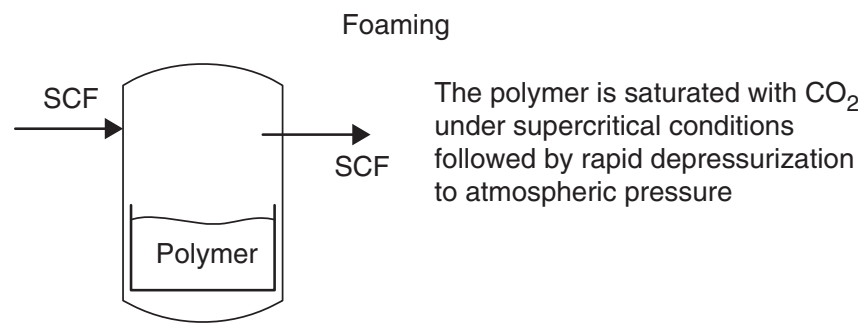

Figure 1. Schematic representation of the SCF foaming process.
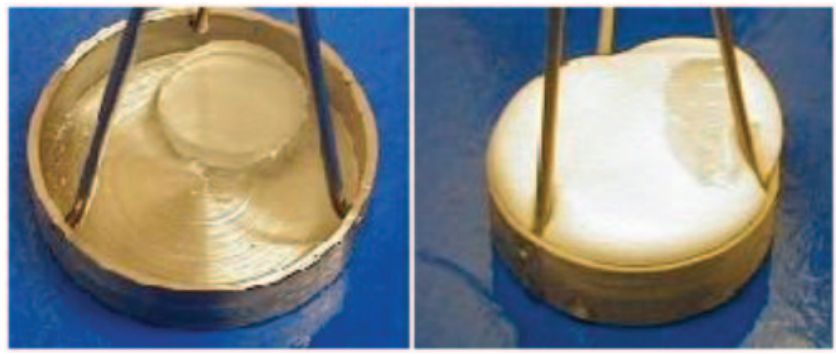

Figure 2. Schematic representation of the supercritical fluid foaming process. 
or blends of different polymers demonstrates the versatility of this technology and shows the potential to develop materials with the desired morphological and mechanical properties. The gas foaming process has also proven to be a very promising technique for the preparation of scaffolds loaded with growth factors and cells. Howdle and coworkers [25] have encapsulated proteins in biocompatible and biodegradable polymers, such as PLA, PLGA, and PCL, at relatively low temperatures and moderate pressures.

An attempt to prepare scaffolds with single and dual protein release from PLA scaffolds was successfully described by Ginty et al. [26]. The ability to generate porous structures in supercritical carbon dioxide, that are able to release basic fibroblastic growth factor (bFGF) [27] or vascular endothelial growth factor (VEGF165) [28] from PLGA was also demonstrated. Another work, by Yang et al. [29] used the same methodology to load the scaffolds with bone morphogenetic protein 2 (BMP2). A nonviral gene delivery system for tissue engineering purposes was developed in a one-step process using supercritical foaming [30].

A critical step in tissue engineering strategies is to achieve high cell seeding efficiencies. The typical procedure is to deposit or inject cell suspensions into the scaffolds. However, in many situations a large portion of the cells is washed out or falls off of the construct during the culturing. Methodologies are needed to induce more efficient contact between cells and scaffold materials. One way, would be to process the material and the cells together in order to obtain a more homogeneous and stable hybrid scaffold. However, cells do not survive in most processing environments except supercritical technologies that could overcome such drawbacks. This would be a major advantage in the field of tissue engineering and regenerative medicine.

A recent study reported by Ginty et al. [31] showed that mammalian cells can survive in a supercritical environment for up to 5 minutes Myoblastic C2C12 cell line, 3T3 fibroblasts, chondrocytes, and hepatocytes were also tested which led to the development of a new injection system for the production of polymer/mammalian cell composites [32]. In a single step, cells are loaded during scaffold processing.

\section{Phase Inversion}

The phase inversion method, also known as immersion precipitation technique, involves casting of a polymer solution onto an inert support followed by immersion of the support with the cast film into a bath filled with a nonsolvent for the polymer. The contact between the solvent and the nonsolvent causes the solution to be phase-separated (Figure 3). 


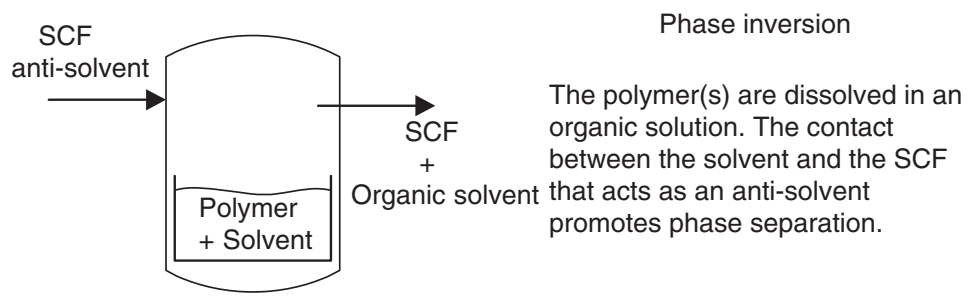

Figure 3. Schematic representation of the SCF phase inversion process.

If the nonsolvent used is a supercritical fluid this adds several advantages to the process. One of the most important advantages of carbon dioxide is the fact that by simply tuning the process conditions, i.e., pressure and temperature, one can tailor the final structure of the product. The advantages of this technique over the conventional phase inversion method are the fact that carbon dioxide can dry the polymer matrix without collapse of the structure due to the absence of a liquid-vapor interface and when carbon dioxide is used as a nonsolvent a subsequent drying step is avoided and the porous structure obtained is a dry product.

The use of carbon dioxide as a nonsolvent for phase separation has been successfully used for the preparation of different polymeric membranes. For the preparation of porous scaffolds two polymers, largely used for biomedical applications, $\operatorname{poly}(L$-lactic acid) [33] and poly(methyl methacrylate), [34] were processed. Porous matrixes from these two materials were produced as well as composite structures were developed $[35,36]$ for tissue engineering and drug delivery devices.

Recently, our group prepared porous structures of starch-based polymers (SPLA) using this technique. It was for the first report of a supercritical fluid assisted phase inversion being used for processing natural-based polymers (Figure 4) [37].

Gas foaming and supercritical assisted phase inversion are two techniques that have been explored for the preparation of 3D matrixes to be used in tissue engineering and regenerative medicine. The principles inherent to each technique limited these applications to certain types of materials. Presented in Table 1 are the technological features that differentiate them.

One of the major differences between gas foaming and the supercritical assisted phase inversion is that in the case of the phase inversion, a polymer solution with organic solvents is needed. Nonetheless, the amount of solvent used is much less compared to the conventional processes. Furthermore, the morphology and properties of the polymers processed can be tuned depending on the technique used and the operating conditions of the process. In a sense, the choice of the 


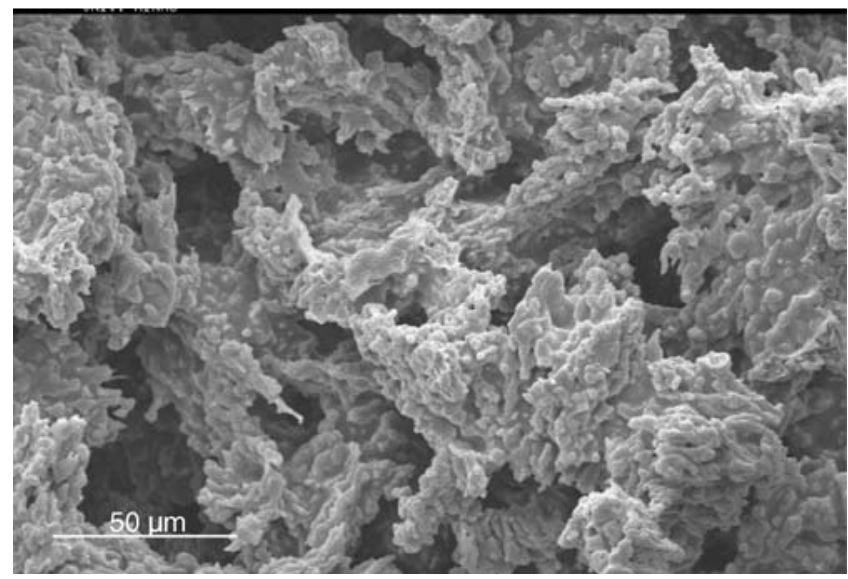

Figure 4. SEM image of a SPLA scaffold prepared by supercritical assisted phaseinversion process.

Table 1. Technological features of the gas foaming and supercritical-assisted phase inversion processes.

\begin{tabular}{lll}
\hline & Gas foaming & Phase inversion \\
\hline Process & Batch & Semicontinuos \\
Role SCF & Solute & Anti-solvent \\
Gas demand & Low & Low to medium \\
Pressure & Low to medium & Low \\
Organic solvent & None & Yes \\
Separation gas/solid & Easy & Easy \\
Separation Gas/solvent & Not applicable & Easy \\
\hline
\end{tabular}

best processing technique relies on the materials to be processed and the final application of the matrix that is being prepared.

\section{IMPREGNATION}

In tissue engineering, the development of a scaffold that can release at a controlled rate, biomolecules and provide biological activity for weeks is very important. Small molecular weight drugs that control proliferation and differentiation of cells could be incorporated into biodegradable scaffolds to induce tissue generation. The scaffold, therefore, plays an important role not only as a physical support but also as a bioactive element able to address adequate signals to cells and tissues.

For effective drug release and delivery, a mobile phase that dissolves and transports the drug component is essential as well as swelling and 
SCF impregnation

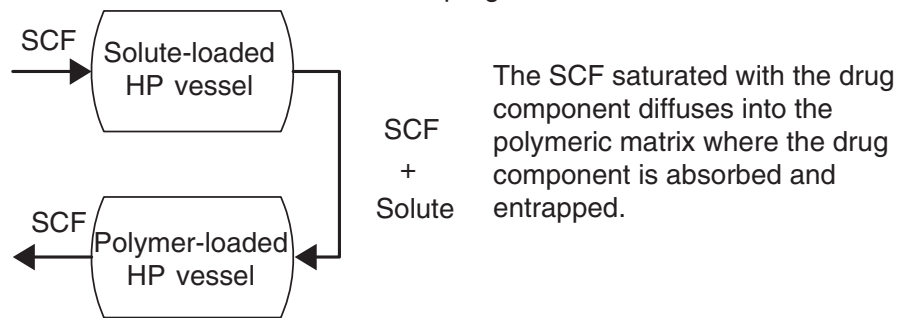

Figure 5. Schematic representation of the SCF impregnation process.

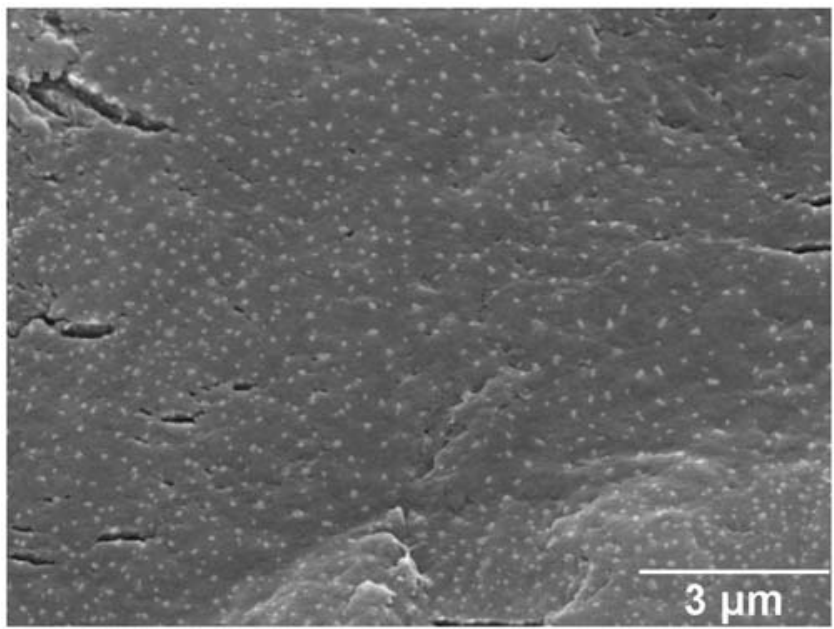

Figure 6. SEM image of an alginate-carragenaan film impregnated with coenzyme Q10.

flexing the polymer matrix to facilitate the diffusion of the drug. Effective scaffold drug impregnation is feasible when the pharmaceutical is soluble in carbon dioxide and the polymer can be swollen by the supercritical fluid (Figure 5). In this case, a highly pure product, free of residual solvents, is obtained, since no organic solvents are involved in the impregnation process [38]. When depressurization occurs, the gas rapidly diffuses out of the polymer, deplasticizing it and warranting the complete removal of solvent, without exposing polymers and drugs to high temperatures [39].

The supercritical fluid impregnation of polymer matrices has been studied mostly for drug delivery systems that are able to sustain drug release for specific time periods [38]. Shown in Figure 6 is a SEM micrograph of a cross section of an alginate-carragenaan film 
impregnated with co-enzyme Q10. The distribution of the reagent is very homogeneous throughout the matrix. Supercritical fluid impregnation is, therefore, a much better process for polymer impregnation because the active components are more homogeneously dispersed and the final product is dry and free of any residual solvent.

Our group has proven the feasibility of preparing a loaded chitosan scaffold able to sustain the release of dexamethasone [40], a steroidal anti-inflammatory agent, which has been reported to effectively induce differentiation of bone marrow stem cells to osteoblasts [41].

Less stable molecules can be also incorporated into matrices using supercritical fluids. Sproule et al. [42] successfully impregnated a protein in PMMA scaffolds without compromising its activity.

Using this technology, it is also possible to impregnate biomolecules with minimal chemical or structural effect in the scaffold. Recently, the impregnation of polycaprolactone fibers prepared by electrospinning was reported [43]. Thus, $\mathrm{CO}_{2}$ impregnation of these scaffolds may provide a method for tailoring the chemistry of these relatively high surface area scaffolds without altering their biomimetic architecture.

Not only pharmaceutical compounds are suitable for impregnation, chemistry can also be done by impregnating monomers into porous matrixes. As a result matrixes with improved properties can be developed. For example, it has been reported in literature, the impregnation of HEMA into alginate foams [44] and PNIPAAm into chitosan scaffolds [45].

\section{STERILIZATION}

Scaffolds, implants, and other medical devices to be used in invasive procedures must be clean and sterilized prior to being used. The most commonly used techniques used for sterilization include; steam autoclaving, gamma irradiation, and chemical treatments with ethylene oxide or hydrogen peroxide plasma [46]. The applicability of each technique is limited to a given material that is dependent on the processing conditions, such as temperature, pressure, and sterilant concentration. Alternatives to these sterilization processes are being studied and supercritical fluid sterilization has been proposed [47]. Intensive research has been carried out in this field and it includes the sterilization of soft tissues, polymers [48], and medical instruments [49]. Zhang et al. [50] has extensively reviewed the current status of highpressure carbon dioxide sterilization. The effect of this technique on vegetative bacterial, bacterial spores and fungi as well as the effects of 
the operating conditions on the growth of microorganisms and effect on their deactivation were evaluated. Although supercritical sterilization process can be applied to a wide range of medical-grade polymers [51], in some cases an interaction between $\mathrm{CO}_{2}$ and the polymer alters the scaffold properties. Thus not all medical-grade polymers can be treated using this process.

\section{OTHER TECHNIQUES}

Other techniques have been described in literature for the preparation of enhanced materials with potential applications in tissue engineering. This is a very recent research field and, therefore, some of these processes are not extensively studied. A new technique, called 'directional freezing of solutions' for the preparation of aligned porous materials was especially conceived to serve as scaffolds for aligned nerve growth [52]. Another research group developed a $\mathrm{CO}_{2}$-assisted assembly method which offers a process suitable for the simultaneous assembly of a large number of micro/nanostructures containing cells and/or biomolecules [53]. In this work, a complex 3D scaffold model was impregnated with mESCs and 3T3 fibroblasts. Recently, a new supercritical fluid-assisted process, in which a polymeric aerogel was prepared with a solid porogen and then, in a subsequent step, the gel was dried using supercritical carbon dioxide was proposed [54].

Surface modification of polymers by graft copolymerization adds unique properties to polymer surfaces. Grafting of polymer surfaces using supercritical carbon dioxide has been tested for the preparation of PVDF membranes [55]. In this process the supercritical $\mathrm{CO}_{2}$, acts as a solvent and carrier agent and accelerates mass transfer of monomers inside polymer matrixes to facilitate the graft copolymerization on the surface of the membrane and within membrane pores.

Another technique for the preparation of 3D structures for tissue engineering using supercritical fluid is assisted injection molding and extrusion. The extrusion process has only been reported for applications in drug delivery and in the preparation of controlled delivery devices $[56,57]$. Nonetheless these techniques can be used in the future in the preparation of porous scaffolds with or without incorporated bioactive compounds. Both supercritical-assisted injection molding and extrusion can be used for polymer blends, which can provide exceptional properties that are characteristic of a homopolymer; commonly, two or more polymers are blended in extruders or batch mixers. Carbon dioxide, as a nonsolvent for most polymers, is a very effective plasticizer, in the foaming process. Hence, supercritical fluid technology is a certain 
potential in this field, not only in processing of blends, but also in the preparation of blends itself.

\section{PERSPECTIVES}

As discussed, supercritical fluids are an interesting alternative to the conventional processes for the processing of biopolymers and bioactive compounds. The literature on this technology is continually expanding. From the preparation of microparticles to the development of 3D structures, supercritical fluids have evolved and now represent a wide range of alternative methods that operate under mild conditions with added advantage of tuning the scaffold properties in the fluid phase. Different research areas, such as polymer precipitation from gas saturated solutions or using $\mathrm{CO}_{2}$ as an anti-solvent, gas foaming, supercritical-assisted phase-inversion, incorporation of bioactive compounds and cells, surface modification, extrusion, and sterilization represent the current trends in supercritical fluid technology for tissue engineering.

Integrating supercritical fluids with other technologies could provide some interesting developments. Materials processed by conventional techniques and subsequently subjected to another processing step could confer new characteristics to the material; for example, the case for polymers is prepared by rapid prototyping techniques, where porosity could be induced in a subsequent step by supercritical fluid foaming. Another example is the use of supercritical fluids for drying purposes. In addition to vacuum drying, and freeze drying, researchers are focusing on supercritical fluids as alternatives for solvent drying. The presence of residual solvents in the final products is of crucial importance in materials for pharmaceutical and biomedical applications. The strict regulatory legislation has been one of the driving forces for the intensive worldwide research and supercritical fluids appear to be an alternative owing to the properties of the fluids themselves.

The novelty of supercritical fluid technology opens a wide range of opportunities for the preparation of enhanced materials as inert structural supports for cell attachment as well as more complex and dynamic environments for tissue development.

\section{ACKNOWLEDGMENTS}

Ana Rita Duarte is grateful for financial support from Fundação para a Ciência e Tecnologia through the grant SFRH / BPD / 34994 / 2007 and through the project PTDC/QUI/69263/2006. 


\section{REFERENCES}

1. Malafaya, P.B., Silva, G.A., Baran, E.T. and Reis, R.L. (2002). Drug Delivery Therapies I: General Trends and its Importance on Bone Tissue Engineering Applications, Curr. Opin. Solid. State Mater. Sci., 6(4): 283-295.

2. Malafaya, P.B., Silva, G.A., Baran, E.T. and Reis, R. L. (2002). Drug Delivery Therapies II.: Strategies for Delivering Bone Regenerating Factors, Curr. Opin. Solid. State Mater. Sci., 6(4): 297-312.

3. Hutmacher, D.W. (2001). Scaffold Design and Fabrication Technologies for Engineering Tissues - State of the Art and Future Perspectives, J. Biomater. Sci. Polym., 12(1): 107-124.

4. Pasquali, I., Betteni, R. and Giordano, F. (2006). Solid-state Chemistry and Particle Engineering with Supercritical Fluids in Pharmaceutics, Eur. J. Pharm. Sci., 27(4): 299-310.

5. Clifford, T. (1998). Fundamentals of Supercritical Fluids, Oxford, Oxford University Press.

6. CPMP/ICH/283/95, ICH Guideline Q3C, Impurities Residual Solvents, 1997.

7. Moroni, L., de Wijn, J.R. and van Blitterswijk, C.A. (2008). Integrating Novel Technologies to Fabricate Smart Scaffolds, J. Biomater. Sci. Polym. Ed., 19(5): 543-572.

8. Fu, Q., Rahaman, M.N., Dogan, F. and Bal, B.S. (2008). Freeze-cast Hydroxyapatite Scaffolds for Bone Tissue Engineering Applications, Biomed. Mat., 3(2): 025005.

9. Sultana, N. and Wang, M. (2008). Fabrication of HA/PHBV Composite Scaffolds Through the Emulsion Freezing/Freeze-drying Process and Characterisation of the Scaffolds, J. Mater. Sci. Mater. Med., 19(7): 2555-2561.

10. Nakamatsu, J., Torres, F.G., Troncoso, O.P., Yuan, M.L. and Boccaccini, A.R. (2006). Processing and Characterization of Porous Structures from Chitosan and Starch for Tissue Engineering Scaffolds, Biomacromolecules, 7(12): 3345-3355.

11. Ghosh, S., Viana, J.C., Reis, R.L. and Mano, J.F. (2007). The Double Porogen Approach as a New Technique for the Fabrication of Interconnected Poly(L-lactic acid) and Starch Based Biodegradable Scaffolds, J. Mater. Sci. Mater. Med., 18(2): 185-193.

12. Gomes, M.E., Ribeiro, A.S., Malafaya, P.B., Reis, R.L. and Cunha, A.M. (2001). A New Approach Based on Injection Moulding to Produce Biodegradable Starch-based Polymeric Scaffolds: Morphology, Mechanical and Degradation Behaviour, Biomaterials, 22(9): 883-889.

13. Ghosh, S., Viana, J.C., Reis, R.L. and Mano, J.F. (2008). Development of Porous Lamellar Poly(l-lactic acid) Scaffolds by Conventional Injection Moulding Process, Acta Biomater, 4(4): 887-896.

14. Gomes, M.E., Azevedo, H.S., Moreira, A.R., Ellä, V., Kellomäki, M. and Reis, R.L. (2008). Starch-Poly( $\varepsilon$-caprolactone) and Starch-poly(lactic acid) 
Fibre-mesh Scaffolds for Bone Tissue Engineering Applications: Structure, Mechanical Properties and Degradation Behaviour, J. Tissue Eng. Reg. Med., 2(5): 243-252.

15. Chevalier, E., Chulia, D., Pouget, C. and Viana, M. (2007). Fabrication of Porous Substrates: A Review of Processes Using Pore Forming Agents in the Biomaterial Field, J. Pharm. Sci., 97(3): 1135-1154.

16. Tuzlakoglu, K., Alves, C.M., Mano, J.F. and Reis, R.L. (2004). Production and Characterization of Chitosan Fibers and 3-D Fiber Mesh Scaffolds for Tissue Engineering Applications, Macromol. Biosci., 4(8): 811-819.

17. Liang, D., Hsiao, B.S. and Chu, B. (2007). Functional Electrospun Nanofibrous Scaffolds for Biomedical Applications, Adv. Drug Del. Rev., 59(14): 1392-1412.

18. Cooper, A.I. (2003). Porous Materials and Supercritical Fluids, Adv. Mater., 15(13): 1049-1059.

19. Mooney, D.J., Baldwin, D.F., Suh, N.P., Vacanti, J.P. and Langer, R. (1996). Novel Approach to Fabricate Porous Sponges of Poly(D,L-lactic-co-glycolic acid) Without the Use of Organic Solvents, Biomaterials, 17(14): 1417-1422.

20. Harris, L.D., Kim, B.S. and Mooney, D.J. (1998). Open Pore Biodegradable Matrices Formed with Gas Foaming, J. Biomed. Mat. Res., 42(3): 396-402.

21. Singh, L., Kumar, V. and Ratner, B.D. (2004). Generation of Porous Microcellular 85/15 Poly((DL)-lactide-co-glycolide) Foams for Biomedical Applications, Biomaterials, 25(13): 2611-2617.

22. Tai, H., Mather, M., Howard, D., Wang, W., White, L.J., Crowe, J.A. et al. (2007). Control of Pore Size and Structure of Tissue Engineering Scaffolds Produced by Supercritical Fluid Processing, Eur. Cells. Mater., 14: 64-77.

23. Mathieu, L.M., Montjovent, M.-O., Bourban, P.-E., Pioletti, D.P. and Manson, J.-A.E. (2005). Bioresorbable Composites Prepared by Supercritical Fluids Foaming, J. Biomed. Mat. Res. A, 75A(1): 89-97.

24. Georgiou, G., Mathieu, L., Pioletti, D.P., Bourban, P.-E., Månson, J.-A.E., Knowles, J.C. et al. (2006). Poly(lactic acid)-Phosphate Glass Composite Foams as Scaffolds for Bone Tissue Engineering, J. Biomed. Mat. Res. B, 80(2): 322-331.

25. Howdle, S.M., Watson, M.S., Whitaker, M.J., Popov, V.K., Davies, M.C., Mandel, F.S. et al. (2001). Supercritical Fluid Mixing: Preparation of Thermally Sensitive Polymer Composites Containing Bioactive Materials, Chem. Commun., 1: 109-110.

26. Sibambo, S.R., Pillay, V., Choonara, Y.E. and Penny, C. (2008). A Novel Salted-out and Subsequently Crosslinked Poly(Lactic-co-Glycolic Acid) Polymeric Scaffold Applied to Monolithic Drug Delivery, J. Bioact. Compat. Polym., 23(2): 132-153.

27. Hile, D.D., Amirpour, M.L., Akgerman, A. and Pishko, M.V. (2000). Active Growth Factor Delivery from Poly(D,L-lactide-co-glycolide) Foams Prepared in Supercritical $\mathrm{CO}_{2}$, J. Controlled Rel., 66(2-3): 177-185. 
28. Kanczler, J.M., Ginty, P.J., Barry, J.J.A., Clarke, N.M.P., Howdle, S.M., Shakesheff, K.M., et al. (2008). The Effect of Mesenchymal Populations and Vascular Endothelial Growth Factor Delivered from Biodegradable Polymer Scaffolds on Bone Formation, Biomaterials, 29(12): 1892-1900.

29. Yang, X.B., Whitaker, M.J., Sebald, W., Clarke, N., Howdle, S.M., Shakesheff, K.M. et al. (2004). Human Osteoprogenitor Bone Formation Using Encapsulated Bone Morphogenetic Protein 2 in Porous Polymer Scaffolds, Tissue Eng., 10(7-8): 1037-1045.

30. Heyde, M., Partridge, K.A., Howdle, S.M., Oreffo, R.O.C., Garnett, M.C. and Shakesheff, K.M. (2007). Development of a Slow Non-viral DNA Release System from $\mathrm{P}_{\mathrm{DL}} \mathrm{LA}$ Scaffolds Fabricated Using a Supercritical $\mathrm{CO}_{2}$ Technique, Biotech. Bioeng., 98(3): 679-693.

31. Ginty, P.J., Howard, D., Rose, F.R.A.J., Whitaker, M.J., Barry, J.J.A., Tighe, P. et al. (2006). Mammalian Cell Survival and Processing in Supercritical $\mathrm{CO}_{2}, P N A S$, 103(19): 7426-7431.

32. Ginty, P.J., Howard, D., Upton, C.E., Barry, J.J.A., Rose, F.R.A.J., Shakesheff, K.M. et al. (2008). A Supercritical $\mathrm{CO}_{2}$ Injection System for the Production of Polymer/Mammalian Cell Composites, J. Supercrit. Fluids, 43(3): 535-541.

33. Tsivintzelis, I., Pavlidou, E. and Panayiotou, C. (2007). Porous Scaffolds Prepared by Phase Inversion Using Supercritical $\mathrm{CO}_{2}$ as Antisolvent I. Poly(L-lactic acid), J. Supercrit. Fluids, 40(2): 317-322.

34. Reverchon, E., Rappo, S.E. and Cardea, S. (2006). Flexible Supercritical $\mathrm{CO}_{2}$-assisted Process for Poly(methyl methacrylate) Structure Formation, Polym. Eng. Sci., 46(2): 188-197.

35. Tsivintzelis, I., Marras, S.I., Zuburtikudis, I. and Panayiotou, C. (2007). Porous Poly(L-lactic acid) Nanocomposite Scaffolds Prepared by Phase Inversion Using Supercritical $\mathrm{CO}_{2}$ as Antisolvent, Polymer, 48(21): 6311-6318.

36. Reverchon, E., Cardea, S. and Rappo, E.S. (2006). Production of Loaded PMMA Structures Using the Supercritical $\mathrm{CO}_{2}$ Phase Inversion Process, J. Membr. Sci., 273(1-2): 97-105.

37. Duarte, A.R.C., Mano, J.F. and Reis, R.L. (2009). Preparation of Starchbased Scaffolds for Tissue Engineering by Supercritical Immersion Precipitation, J. Supercrit. Fluids, doi:10.1016/j.supflu.2008.12.008.

38. Kikic, I. and Vecchione, F. (2003). Supercritical Impregnation of Polymers, Curr. Opin. Solid State Mater. Sci., 7(4-5): 399-405.

39. Kazarian, S.G. (2004). Supercritical Fluid Impregnation of Polymers for Drug Delivery, In: York, P., Kompella, U.B. and Shekunov, B.Y. (eds), Supercritical Fluid Technology for Drug Product Development, pp. 343-366, New York, Marcel Dekker.

40. Duarte, A.R.C., Mano, J.F. and Reis, R.L. (2008). Preparation of Chitosan Scaffolds Loaded with Dexamethasone for Tissue Engineering Applications 
Using Supercritical Fluid Technology, European Polymer Journal, 45(1): 141-148.

41. Yoon, J.J., Kim, J.H. and Park, T.G. (2003). Dexamethasone-releasing Biodegradable Polymer Scaffolds Fabricated by a Gas-foaming/Salt-leaching Method, Biomaterials, 24(13): 2323-2329.

42. Sproule, T.L., Lee, J.A., Li, H., Lannutti, J.J. and Tomasko, D.L. (2004). Bioactive Polymer Surfaces Via Supercritical Fluids, J. Supercrit. Fluids., 28(2-3): 241-248.

43. Ayodeji, O., Graham, E., Kniss, D., Lannutti, J. and Tomasko, D. (2007). Carbon Dioxide Impregnation of Electrospun Polycaprolactone Fibers, J. Supercrit. Fluids., 41(1): 173-178.

44. Partap, S., Hebb, A.K., Rehman, I.U. and Darr, J.A. (2007). Formation of Porous Natural-synthetic Polymer Composites Using Emulsion Templating and Supercritical Fluid Assisted Impregnation, Polym. Bulletin, 58(2): 849-860.

45. Temtem, M., Casimiro, T., Mano, J.F. and Aguiar-Ricardo, A. (2007). Green Synthesis of a Temperature Sensitive Hydrogel, Green Chemistry, 9(1): $75-79$.

46. Matthews, M.A., Warner, L.S. and Kaiser, H. (2001). Exploring the Feasibility of Using Dense-phase Carbon Dioxide for Sterilization, Med. Device Diagn. Ind., 5: 140-149.

47. Dillow, A.K., Langer, R.S., Foster, N. and Hrkach, J.S. (2000). Supercritical Fluid Sterilization Method, United States Patent, US 6149864.

48. Kafesjian, R. and Howanec, M.J.R. (2003). Supercritical Fluid Extraction Process for Tissue Preparation, United States Patent Application Publication, Pub. No. US 2003/072677 A1.

49. Kanno, M. (2003). Method of Sterilizing Medical Instruments, United States Patent, US 6610251 B1.

50. Zhang, J., Davis, T.A., Matthews, M.A., Drews, M.J., LaBerge, M. and An, Y.H. (2006). Sterilization Using High-pressure Carbon Dioxide, J. Supercrit. Fluids., 38(3): 354-372.

51. Jiménez, A., Thompson, G.L., Matthews, M.A., Davis, T.A., Crocker, K., Lyons, J.S. et al. (2007). Compatibility of Medical-grade Polymers with Dense $\mathrm{CO}_{2}$, J. Supercrit. Fluids, 42(3): 366-372.

52. Zhang, H., Long, J. and Cooper, A. I. (2005). Aligned Porous Materials by Directional Freezing of Solutions in Liquid $\mathrm{CO}_{2}$, J. Am. Chem. Soc., 127(39): 13482-13483.

53. Yang, Y., Xie, Y., Kang, X., Lee, L.J. and Kniss, D.A. (2006). Assembly of Three-dimensional Polymeric Constructs Containing Cells/Biomolecules Using Carbon Dioxide, J. Am. Chem. Soc., 128(43): 14040-14041.

54. Reverchon, E., Cardea, S. and Rapuano, C. (2008). A New Supercritical Fluid-based Process to Produce Scaffolds for Tissue Replacement, J. Supercrit. Fluids., 45(3): 356-364. 
55. Qiu, G.-M., Zhua, L.-P., Zhua, B.-K., Xu, Y.-Y. and Qiu, Q.L. (2008). Grafting of Styrene/Maleic Anhydride Copolymer onto PVDF Membrane by Supercritical Carbon Dioxide: Preparation, Characterization and Biocompatibility, J. Supercrit. Fluids., 45(3): 374-383.

56. Verreck, G., Decorte, A., Li, H., Tomasko, D., Arien, A., Peeters, J. et al. (2006). The Effect of Pressurized Carbon Dioxide as a Plasticizer and Foaming Agent on the Hot Melt Extrusion Process and Extrudate Properties of Pharmaceutical Polymers, J. Supercrit. Fluids., 38(3): 383-391.

57. Lyons, J.G., Hallinan, M., Kennedy, J.E., Devine, D.M., Geever, L.M., Blackie, P. et al. (2007). Preparation of Monolithic Matrices for Oral Drug Delivery Using a Supercritical Fluid Assisted Hot Melt Extrusion Process, Int. J. Pharm., 329(1-2): 62-71. 